\title{
REVIEW
}

\section{Resting state functional MRI in Alzheimer's Disease}

\author{
Prashanthi Vemuri**1, David T Jones ${ }^{2}$ and Clifford R Jack Jr.'
}

\begin{abstract}
Resting-state functional magnetic resonance imaging (fMRI) is emerging as an interesting biomarker for measuring connectivity of the brain in patients with Alzheimer's disease (AD). In this review, we discuss the origins of resting-state $\mathrm{fMRl}$, common methodologies used to extract information from these fourdimensional fMRI scans, and important considerations for the analysis of these scans. Then we present the current state of knowledge in this area by summarizing various $A D$ resting-state $\mathrm{FMRI}$ studies presented in the first section and end with a discussion of future developments and open questions in the field.
\end{abstract}

Alzheimer's disease (AD) is a multifaceted disease in which cumulative pathological brain insults result in progressive cognitive decline that ultimately leads to dementia. Amyloid plaques, neurofibrillary tangles, and neurodegeneration are the well-established pathological hallmarks of $\mathrm{AD}$. In addition to existing imaging biomarkers to measure each of these pathologies, restingstate functional magnetic resonance imaging (rs-fMRI) is an emerging $\mathrm{AD}$ biomarker that provides a non-invasive method to measure subtle functional changes in the brain. The most salient feature of rs-fMRI in AD is the ease of data acquisition in patients with dementia, specifically the ability to measure functional connectivity changes without requiring the performance of a task. Also, this MRI sequence can be obtained easily during routine clinical structural MRI sessions. This paper provides a review of rs-fMRI in AD and is divided into three sections: (a) the origins of rs-fMRI, methods that are widely used, and pitfalls that are typically seen in rsfMRI studies; (b) the published resting-state literature in $\mathrm{AD}$, and (c) a discussion of future developments and open questions in the field.

\footnotetext{
*Correspondence: vemuri.prashanthi@mayo.edu

'Department of Radiology, Mayo Clinic and Foundation, 200 First Street SW, Rochester, MN 55905, USA

Full list of author information is available at the end of the article
}

\section{A. Low-frequency fluctuations: origins, methods, and pitfalls \\ Origins}

Resting-state fMRI is a relatively recent addition to the tools used by the neuroscientific community to investigate the functional connectivity in the human brain. The foundations of functional connectivity began to emerge in the 1960s when neurophysiologists, who were studying action potential firing trains from single neurons, recognized the importance of characterizing the relationship of one neuron's firing pattern to other neurons firing at the same time [1]. At its most rudimentary level, functional connectivity represents a measure of the correlated signal from two or more spatially distinct regions over time. Over the years, this concept has been applied to a variety of techniques used in neuroscience (for example, electroencephalography, magnetoencephalography, and corticography). However, it was not employed in fMRI until the 1990s [2], and not until 1995 did investigators first observe that low-frequency fluctuations $(0.1$ to $0.01 \mathrm{~Hz})$ in the blood oxygen level-dependent (BOLD) signal were highly correlated within the motor cortex [3]. These low-frequency fluctuations have since been shown to be specific to gray matter $[3,4]$ and can be used to identify the spatial extent of temporally correlated networks of structural and functional connectivity within the brain [5-9]. These largescale networks are present at all times in the living human brain, and analysis of task-based fMRI experiments gives results similar to those of 'resting state' fMRI paradigms when subjects are not given a specific task [10]. The importance of this finding cannot be understated and implies that large-scale networks of functional connectivity that are interrogated with task-based fMRI paradigms are the same networks interrogated during fMRI paradigms that do not have a specific task (that is, rs-fMRI). Task-based fMRI paradigms are likely interrogating a specific arrangement of the underlying largescale networks of functional connectivity within the context of the experimental paradigm, whereas rs-fMRI studies interrogate these same networks without an experimentally determined context. The absence of a predetermined experimental task in rs-fMRI is the feature that led to the use of the moniker 'resting state' to describe this technique and the identified networks (that 
is, resting-state networks). However, given that these networks are present during tasks and that no brain is ever truly at 'rest', some investigators have offered the more accurate term of intrinsic connectivity networks (ICNs) [11] rather than resting-state networks. Use of the ICN moniker is gaining popularity and we will use this term for the remainder of the review. For the same reasons, we prefer the term task-free fMRI (TF-fMRI) rather than rs-fMRI. The absence of a predetermined experimental paradigm in TF-fMRI precludes the use of traditional fMRI methods for modeling the hemodynamic response related to experimentally isolated changes in the BOLD signal. Therefore, we will briefly review some of the most popular methods currently used to investigate ICNs in TF-fMRI and discuss potential confounds that these techniques are susceptible to before discussing the application of these techniques to studies related to AD.

\section{Methods}

Several methods have been developed to extract the spatial and temporal extent of ICNs from TF-fMRI data $[12,13]$. The dominant methodologies can be segregated into region of interest-based or seed-based correlation studies and data-driven multivariate analysis techniques, such as independent component analysis (ICA), and are described in detail here.

\section{Seed-based correlation studies}

Seed-based techniques have an a priori assumption that the node or region involved in the ICN is known and these regions are used to extract the low-frequency fluctuations in the BOLD signal used in further analysis. The seed regions may consist of individual voxels, small collections of voxels within a spheroid seed, or large functionally/anatomically derived regions of interest (for example, Brodmann areas). The low-frequency fluctuations within this defined seed or region can then be correlated with every other voxel in the brain in a voxelwise exploratory analysis to understand the seed-to-brain connectivity (Figure 1a) or can be correlated only with another region or seed to analyze seed-to-seed connectivity. The sensory-motor ICN was first demonstrated in fMRI by using a seed-based methodology [3], as was the prominent ICN known as the default mode network (DMN) [14] (see section B, 'Task-free functional magnetic resonance imaging Alzheimer's disease studies'). An example of the positive correlations in a seed-to-brain analysis using a spheroid seed of $6-\mathrm{mm}$ radius in the posterior cingulate - MNI (Montreal Neurological Institute) coordinates $=(-3,-51,24)-$ is shown in Figure 1a, and the negative correlations to the same seed are shown in Figure 2a.

Alternatively, the correlations of the low-frequency fluctuations within a series of regions or seeds can be organized into a connectivity matrix (as shown in Figure 3) and subjected to graph theoretical or network analysis [15]. Network analysis is a powerful tool that enables us to characterize the global as well as local functional connectivity characteristics of a group of nodes in the brain and provides us with a simple way to comprehensively compare the functional connectivity organization of the brain between patients and controls. The network metrics that can be characterized are thoroughly discussed in [16] and include functional segregation, integration, and resilience of the network to insult.

\section{Data-driven methods}

ICA is a data-driven multivariate analysis method that can be used to separate any multivariate signal into subcomponents that are mutually statistically independent. Since the fMRI signal observed is a summation of signals from multiple independent networks (ICNs) in the brain, ICA is ideally suited to separate each of the ICNs. ICA does not necessitate the a priori definition of regions from which low-frequency fluctuations are to be extracted and can extract ICNs by determining the maximal spatial and temporal independence of signals in the TF-fMRI data. This can be done at both the subject and group levels [17]. Examples of several ICNs that were identified as independent components at the group level in the same data used in the seed analyses are displayed in Figures $1 \mathrm{~b}$ and $2 \mathrm{~b}$. These group-level ICNs can then be used to back-reconstruct individual subject ICNs [18].

\section{Pitfalls}

Several special considerations need to be accounted for while analyzing TF-fMRI studies. Some of the more prominent issues are listed here:

\section{Signal contamination}

All of these analyses necessitate several preprocessing steps to avoid signal contamination from non-neuronal sources of fluctuations in the signal time course, most prominently from movement and low-frequency oscillations induced from the cardiac and respiratory cycle [19]. Regressing out nuisance covariates (that is, bulk head motion parameters, white matter signal, cerebrospinal fluid signal, and global signal) from the signal time courses attempts to deal with these confounds [20]. However, bulk head motion may remain as a significant confound, specifically in patients with dementia; therefore, scanning sessions contaminated by significant motion are typically excluded from subsequent analysis. Removal of global mean signal improves the specificity of connectivity analysis [20] and is an attractive alternative to using physiologic cardiac and respiratory inputs as regressors [19] for reducing spurious direct correlations 


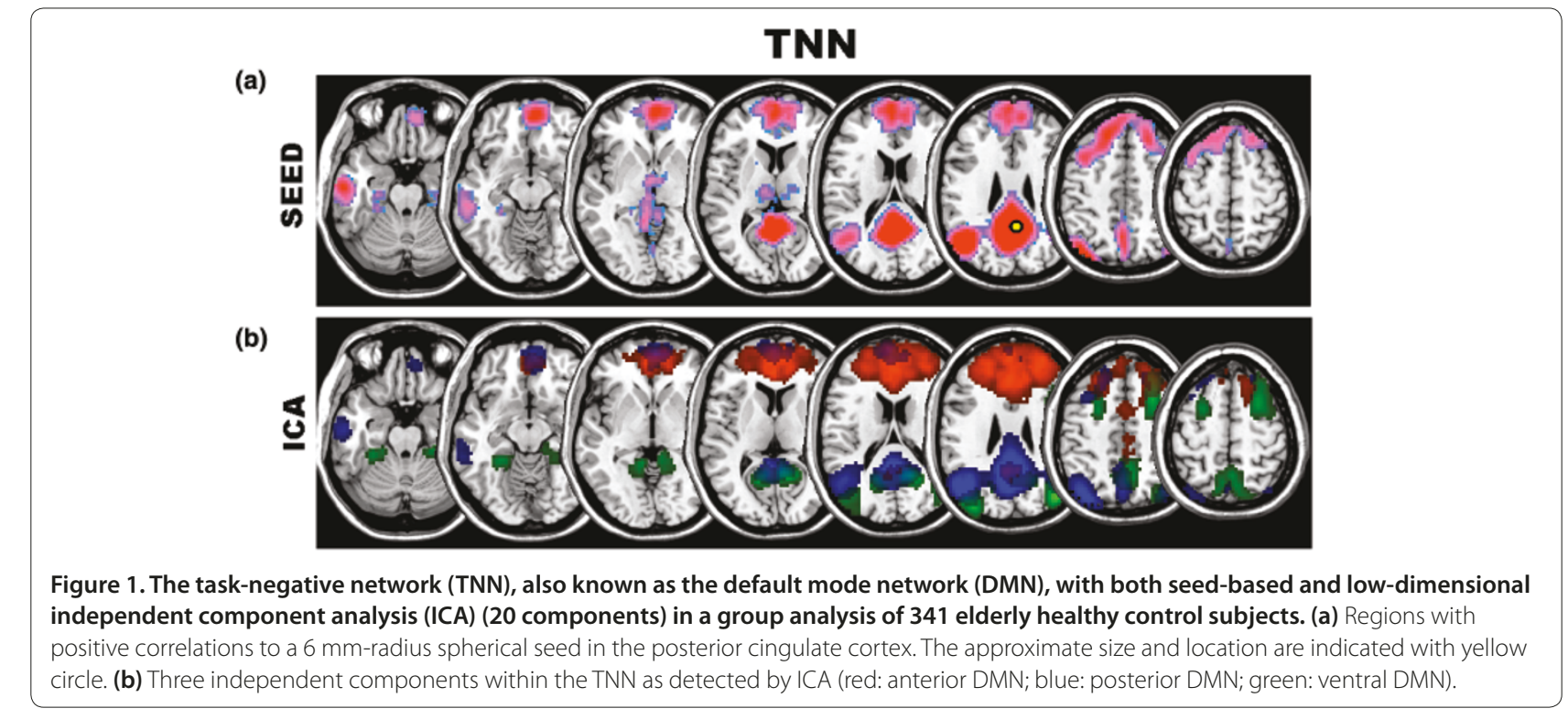

\section{(a)}

\section{TPN}

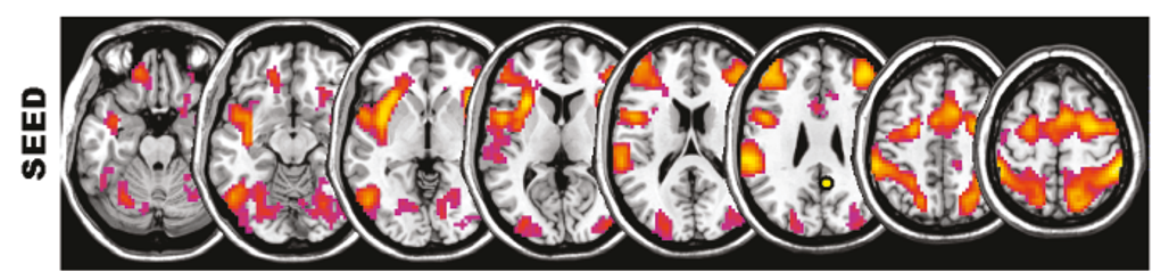

(b)

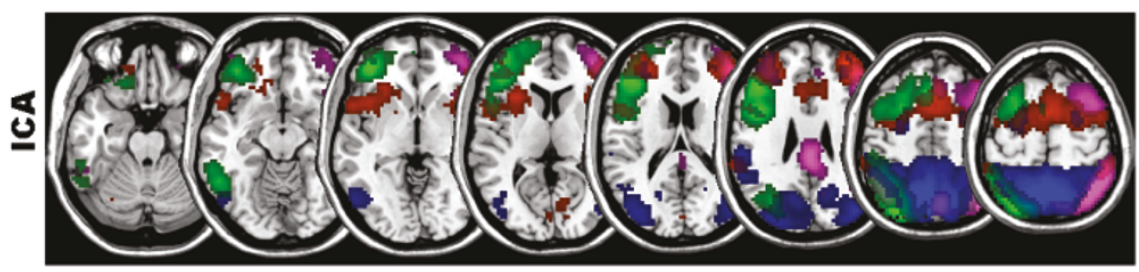

Figure 2. The task-positive network (TPN) with both seed-based and low-dimensional independent component analysis (ICA) (20 components) in a group analysis of 341 elderly healthy control subjects. (a) Regions with negative correlations, also known as anticorrelations, to the same $6 \mathrm{~mm}$-radius spherical seed in the posterior cingulate cortex used in Figure 1. The approximate size and location are indicated with yellow circle. (b) Four independent components within the TPN (red: salience network; blue: dorsal attention network; green: left executive control network; violet: right executive control network) that were detected using ICA.

when MRI-compatible physiologic measuring systems are not available. This is necessary because gray matter has a capillary density significantly greater than that of white matter [21] and this variability is not accounted for by cerebral spinal fluid and white matter regression alone [20]. However, this increases the regions that have negative correlations or so-called 'anti-correlations' as the mean value for all voxels at every time point will be zero [22]. Figure 1a shows the positive correlations, and Figure 2a shows the negative correlations (that is, anticorrelations). Surprisingly, the regions that are anticorrelated are consistent within and between subjects for any given seed; however, the physiologic meaning of this relationship remains uncertain. This relationship is most prominent between regions defined as the task-positive network and the task-negative network [23]. Subregions within both of these anti-correlated ICNs seen in the seed analysis are identifiable with ICA applied to the same data (Figures $1 \mathrm{~b}$ and $2 \mathrm{~b}$ ).

\section{Age- and gender-related signal variability}

The growth and development of ICNs have been observed through infancy into adulthood [9,24-26]. In addition, group comparisons of functional connectivity between young adults and the elderly in two nodes of the DMN have demonstrated age-associated disconnection 


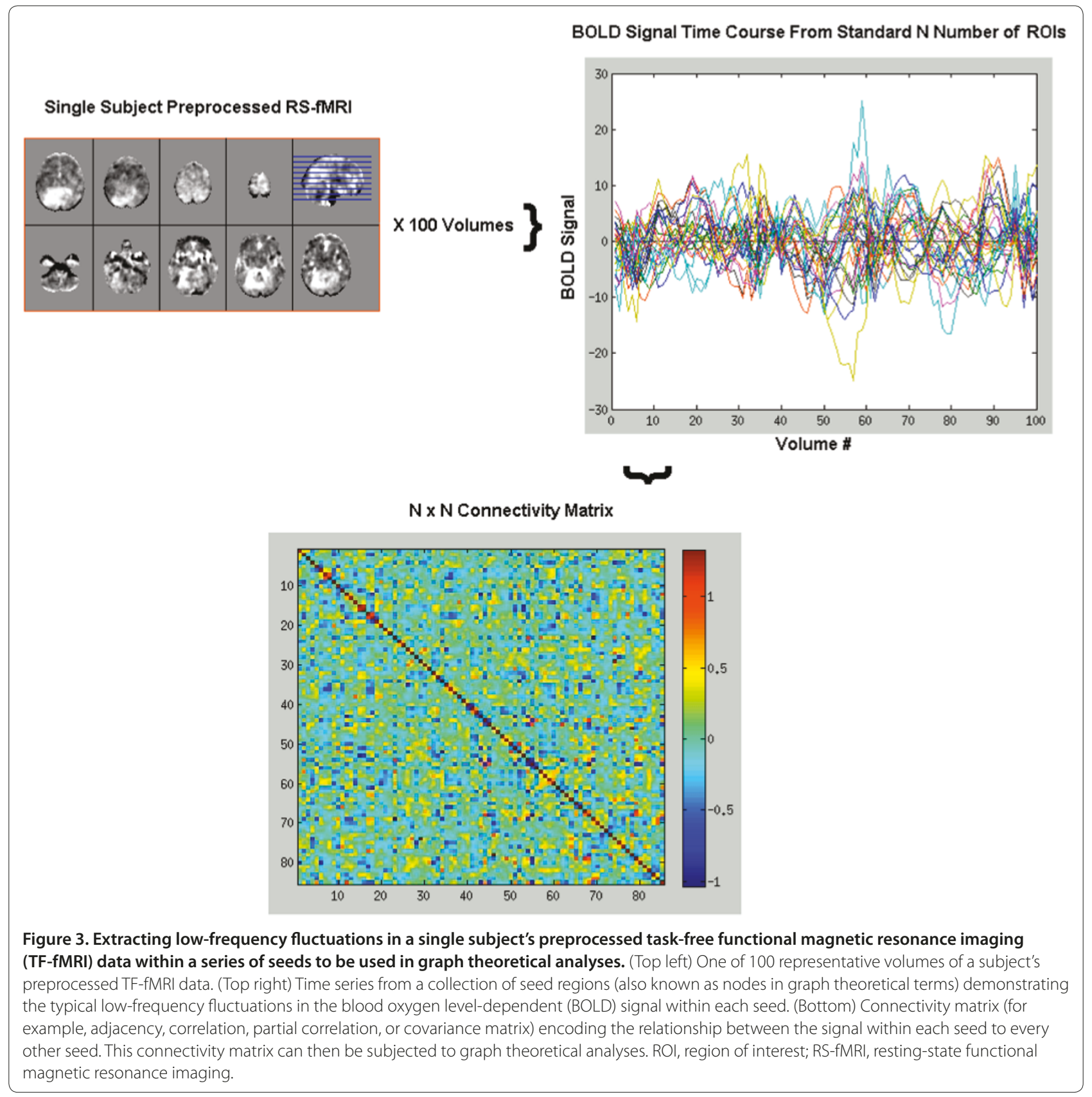

of anterior to posterior regions [27]. Also, a recent publication of a large multicenter cohort analyzed with both seed-based voxel-wise methods and ICA has demonstrated a significant age and gender effect on connectivity [28]. These studies suggest that there is a significant amount of change within ICN throughout the lifespan. Work from our lab recently demonstrated that the age effect on ICNs is accelerated in AD, further emphasizing the importance of understanding and accounting for the effect of age on TF-fMRI investigations of neurodegenerative illnesses [29].

\section{Number of independent components in independent component analysis}

Theoretically, the total or maximum number of ICNs is not deterministic in every human brain; therefore, setting the total number of independent components (or networks) that need to be extracted using ICA is ambiguous. If the number of independent components is set lower than the total number of ICNs in the brain, multiple ICNs might be fused together and not be well separated. On the other hand, specifying a larger number of independent components may split the existing ICNs 
into two or more subsystems (as shown by different ICNs detected by different colors in Figures $1 \mathrm{~b}$ and $2 \mathrm{~b}$ ). While this remains an open question, recent studies have suggested that 20 independent components may be a reasonable assumption [10]. An additional point to note while looking at the networks from an ICA is that some components may contain artifacts that can be used to denoise subsequent analyses [30].

\section{B. Task-free functional magnetic resonance imaging Alzheimer's disease studies}

As mentioned above, rs-fMRI or TF-fMRI is becoming increasingly popular in the field of AD biomarkers. In this section, we present various published studies that have used the methods discussed in section A. We have broadly categorized the various TF-fMRI studies in AD and mild cognitive impairment (MCI) (prodromal stage of $\mathrm{AD}$ ) into six groups and discuss the current state of knowledge in each of these.

\section{Network-based studies in Alzheimer's disease}

Functional imaging studies using positron emission tomography (PET) as well as fMRI have repeatedly observed the presence of deactivation in consistent brain regions in response to a task. This observation, along with the fact that the same regions have higher blood flow and oxygen consumption at rest, led to the conclusion that specific regions have higher baseline activity that is turned off during any task-induced state [31]. These regions include the posterior cingulate, precuneus, medial prefrontal cortex and the hippocampus and are thought to be part of a DMN [31]. The first studies in this area showed that there is decreased precuneus deactivation during tasks [32] and decreased DMN connectivity [33] in AD. Since the regions in the DMN (specifically, the hippocampus) are related to episodic memory, DMN is the most studied network in AD [33]. Studies have also shown decreased functional synchrony in the hippocampus [34] and reduced connectivity of the hippocampus to the rest of the DMN [35].

As mentioned above, several consistent ICNs other than the DMN operate synchronously in the resting brain (for example, motor function, visual processing, executive functioning, auditory processing, and episodic memory). Sorg and colleagues [36] were the first to study eight consistent networks in subjects with increased risk for AD by using ICA and found that two networks, namely the DMN and executive attention, had significantly reduced connectivity in patients with amnestic MCI when compared with cognitively normal $(\mathrm{CN})$ subjects. Several task-associated studies have also investigated the effect of $\mathrm{AD}$ on several components of the memory networks - a key domain affected in AD [37-39].

As a heteromodal region - a hub for the majority of the information processing in the brain and a region of significant hypometabolism and amyloid deposition in $\mathrm{AD}$ - precuneus/posterior cingulate (PPC) is the most studied region in fMRI AD studies [40]. There has been evidence that disease-related regional coherence of the region is decreased [41] and that functional disconnection of this region precedes atrophy [42]. Whereas some studies have shown reduced connectivity of this region to the brain early in the disease process [43,44], others have found notable increased connectivity [43,45-47]. Recent papers have also been trying to investigate whether the PPC connectivity changes are due to regional pathology. Frings and colleagues [48] found that patients with early frontotemporal dementia have PPC connectivity changes similar to those of patients with AD or MCI, suggesting that PPC disconnection is a function of a lack of connectivity and not local pathology. Mormino and colleagues [49] found that, even though DMN is altered by increasing global amyloid levels, there was little effect of regional amyloid levels on regional functional connectivity. Different studies have used different methodologies that are quantitatively dissimilar and have used different populations to investigate this question, making it difficult to interpret the overall effect of $\mathrm{AD}$ on network connectivity. However, recently, the field has been moving toward the understanding that there is reduced DMN connectivity posteriorly with concomitant frontal lobe increases in the DMN [29] and the salience network $[50,51]$. The interpretation of these reciprocal changes is a matter of ongoing investigation [52]. However, we have found that this pattern is technique-independent and correlates with cognitive function [29], which suggests that both the increases and decreases in connectivity may be signs of ICN disorganization due to AD. However, this AD-related network disorganization may be modified with disease progression, as demonstrated by two recent longitudinal studies that found that the increased connectivity was present early in the diseases course but declines in later stages $[53,54]$.

\section{Large-scale network analysis}

Seed-based network detection (such as seed-to-brain connectivity) and ICA-based network detection are limited since they can be used to study specific networks based on a priori knowledge. For this reason, large-scale network analyses are becoming increasingly popular to investigate the functional connectivity across the entire brain in an unbiased fashion. The simplest large-scale network analyses have used the 116 anatomically defined regions in the Automated Anatomical Labeling (AAL) atlas [55] and estimated correlations between any two regions to obtain a connectivity matrix of $116 \times 116$ that represents connectivity between all gross anatomical regions of the brain (similar to the example shown in Figure 3). Wang and colleagues showed that there is 
decreased anterior-posterior disconnection in $\mathrm{AD}$ on the basis of these $116 \times 116$ correlation matrices [56] and that correlations between 22 of the task-positive and task-negative regions can be used to distinguish patients with AD from CN patients with an accuracy of 83\% [57]. Studies have also used these matrices and found patterns of abnormal interregional correlations in widely dispersed brain areas in amnestic MCIs [58,59].

Furthermore, the information in these matrices can be condensed into global connectivity measures by using graph theory and network analysis (as mentioned above) and can be applied to detect the disruption in the organization of the functional brain networks in $\mathrm{AD}$ (as presented in $[60,61])$. Supekar and colleagues [61] found that there is disruption of local connectivity in the brain (specifically, in the hippocampus) reflected by low-clustering coefficients in AD when compared with CN subjects. Sanz-Arigita and colleagues [60] found, on the other hand, that the primary effect of $\mathrm{AD}$ was on the decreased long-distance connectivity of the frontal and caudal brain regions.

Until recently, anatomically defined regions have been used to investigate large-scale networks of the brain. However, using anatomically defined regions has the following drawbacks: (a) the brain has a complex functional architecture and the functional units are smaller in size, making spatial averaging of time courses over large structural anatomy very unreliable; and (b) anatomical regions of interest may not always correspond to the functional organization of networks. Therefore, the field is moving toward finer sampling of the fMRI scans $[40,62]$ and using functionally defined regions [63] to obtain a better picture of the local and global functional changes.

\section{Genetic effects}

Apolipoprotein E (APOE) $\varepsilon 4$ is the most important known genetic risk factor for typical late-onset AD. The lifetime risk of developing $\mathrm{AD}$ is increased and the age of onset of the disease is decreased with increasing number of APOE $\varepsilon 4$ alleles [64]. Studies have shown that APOE $\varepsilon 4$ carriers and non-carriers have dissimilar functional connectivity networks in younger adults [65] as well as older adults [51,66]. In a recent study, Sheline and colleagues [67] showed that there is altered connectivity in $\mathrm{APOE} \varepsilon 4$ carriers before the onset of amyloid plaque formation, suggesting that the genetic effect of APOE is seen even before any pathological changes. These studies suggest that it is important to take into account the functional architecture differences due to genetics.

\section{Amyloid deposition and functional connectivity in Alzheimer's disease}

Amyloid deposition is widely believed to be an early process in $\mathrm{AD}$ and by itself does not directly cause clinical symptoms [68]. Pittsburgh compound B (PIB)
PET scans have commonly been used as a surrogate for amyloid deposition [69] in recent fMRI AD studies. Recent literature has consistently shown that there is a disruption of functional connectivity (especially, DMN) in subjects with amyloid deposition but no cognitive impairment [43,44,49,70-72]. However, whether these early changes to the functional architecture are a compensatory mechanism to amyloid toxicity or a cause of amyloid deposition needs to be further investigated [73].

\section{Measuring efficacy of therapeutics}

At present, AD biomarkers have not yet been validated as surrogate endpoints for regulatory purposes and therefore cannot be used as the primary indicators of efficacy. However, there is a search for biomarkers that are noninvasive (to use for serial measurements) as well as sensitive (to perform clinical trials with smaller sample sizes). fMRI has always been viewed as a potential candidate since it can capture subtle pharmacodynamic effects on brain connectivity. TF-fMRI is of particular interest since its effect size is 2.4 times better than that of encoding-associated fMRI techniques in distinguishing risk groups and much easier to set up on clinical scanners because no additional specialized hardware or software is needed [66]. A recent study showed that TF-fMRI can detect the effect of symptomatic treatment for moderate AD over 6 months [74].

\section{Differential diagnosis of dementias}

Given that pathology does not always map onto the clinical expression of the disease and has considerable clinical heterogeneity, biomarkers (such as TF-fMRI) that can provide information about the various functional networks may aid in the differential diagnosis of dementia types. Functional deactivation [75] and rs-fMRI differences [76] have been shown to be different between subjects with dementia with Lewy bodies and AD. While Frings and colleagues [48] showed that patients with early frontotemporal dementia have PPC connectivity changes similar to those of patients with $\mathrm{AD}$ or $\mathrm{MCI}$, Zhou and colleagues [50] showed that subjects with frontotemporal dementia have reduced salience network activity and increased DMN activity, which is exactly the opposite of the AD effect. The apparent discrepancy between these two studies highlights the importance of understanding the differences between task-induced deactivations in a network and task-free measure of withinnetwork functional connectivity, and one should not conclude that the same networks are targeted in $\mathrm{AD}$ and frontotemporal dementia. As suggested by Seeley and colleagues [77], different syndromic atrophy foci may be related to the disruption of different large-scale networks and TF-fMRI may aid in both making a differential 
diagnosis as well as distinguishing the disease mechanisms of different dementias.

\section{Future developments and open questions}

TF-fMRI can potentially add value to clinical assessment since it is an independent non-invasive measure of neuronal activity that cannot be captured by using structural brain scans. TF-fMRI has the potential to play several key roles in AD: making an early diagnosis, predicting future progression of disease, and measuring the efficacy of therapeutics and progression of disease. However, there are still issues that need to be systematically solved before TF-fMRI is ready for clinical applications.

Some of the necessary future developments in the field of TF-fMRI are (a) standardization of preprocessing methods for TF-fMRI scans, (b) development of analysis methodologies to extract information from TF-fMRI scans so that the measures are sensitive to detecting small functional changes and have good reproducibility, and (c) establishment of large population-based TF-fMRI databases to evaluate the variability and stability of largescale networks in the general population.

The above developments will aid us in answering some important open questions in the field of TF-fMRI in AD: Is there a consistent breakdown of the functional architecture in AD because of increasing pathology? Do functional changes occur before or after the pathological changes due to $\mathrm{AD}$ ? That is, are functional changes a response to pathology or catalysts to AD-related pathological changes? If there is a specific signature of functional architecture for each dementia, how can these be applied to provide a robust differential diagnosis and aid the clinical diagnosis of patients in the prodromal stages of dementia?

\section{Abbreviations}

AD, Alzheimer's disease; APOE, apolipoprotein E; BOLD, blood oxygen leveldependent; CN, cognitively normal; DMN, default mode network; fMRI, functional magnetic resonance imaging; ICA, independent component analysis; ICN, intrinsic connectivity network; $\mathrm{MCl}$, mild cognitive impairment; MRI, magnetic resonance imaging; PET, positron emission tomography; PPC, precuneus/posterior cingulate; rs-fMRI, resting-state functional magnetic resonance imaging; TF-fMRI, task-free functional magnetic resonance imaging.

\section{Competing interests}

CRJ serves on scientific advisory boards for Elan Corporation/Janssen Alzheimer Immunotherapy (Dublin, Ireland), Eli Lilly and Company (Indianapolis, IN, USA), GE Healthcare (Little Chalfont, Buckinghamshire, UK), and Eisai Inc. (Woodcliff Lake, NJ, USA); receives research support from Baxter International Inc. (Deerfield, IL, USA), Allon Therapeutics Inc. (Vancouver, BC, Canada), and Pfizer Inc (New York, NY, USA); and holds stock/stock options in Johnson \& Johnson (New Brunswick, NJ, USA). PV and DTJ declare that they have no competing interests.

\section{Acknowledgments}

PV receives support from National Institute on Aging grant K99 AG37573 (as principal investigator) and an Alzheimer's Association New Investigator Research Grant. CRJ receives support from National Institute on Aging grants R01 AG11378 (as principal investigator), P50-AG16574 (as co-investigator), and U01 AG024904-01 (as co-investigator) and the Alexander Family Alzheimer's Disease Research Professorship of the Mayo Foundation.

\section{Author details}

'Department of Radiology, Mayo Clinic and Foundation, 200 First Street SW, Rochester, MN 55905, USA. ${ }^{2}$ Department of Neurology, Mayo Clinic and Foundation, 200 First Street SW, Rochester, MN 55905, USA.

Published: 10 January 2012

\section{References}

1. Moore GP, Perkel DH, Segundo JP: Statistical analysis and functional interpretation of neuronal spike data. Annu Rev Physiol 1966, 28:493-522.

2. Friston KJ, Jezzard P, Turner R: Analysis of functional MRI time-series. Hum Brain Mapp 1994, 1:153-171.

3. Biswal B, Yetkin FZ, Haughton VM, Hyde JS: Functional connectivity in the motor cortex of resting human brain using echo-planar MRI. Magn Reson Med 1995, 34:537-541.

4. Li SJ, Biswal B, Li Z, Risinger R, Rainey C, Cho JK, Salmeron BJ, Stein EA: Cocaine administration decreases functional connectivity in human primary visual and motor cortex as detected by functional MRI. Magn Reson Med 2000, 43:45-51

5. Chen K, Reiman EM, Huan Z, Caselli RJ, Bandy D, Ayutyanont N, Alexander GE: Linking functional and structural brain images with multivariate network analyses: a novel application of the partial least square method. Neuroimage 2009, 47:602-610.

6. Damoiseaux JS, Rombouts SA, Barkhof F, Scheltens P, Stam CJ, Smith SM, Beckmann CF: Consistent resting-state networks across healthy subjects. Proc Natl Acad Sci U S A 2006, 103:13848-13853.

7. Damoiseaux JS, Greicius MD: Greater than the sum of its parts: a review of studies combining structural connectivity and resting-state functional connectivity. Brain Struct Funct 2009, 213:525-533.

8. Greicius MD, Supekar K, Menon V, Dougherty RF: Resting-state functional connectivity reflects structural connectivity in the default mode network. Cereb Cortex 2009, 19:72-78.

9. Supekar K, Uddin LQ, Prater K, Amin H, Greicius MD, Menon V: Development of functional and structural connectivity within the default mode network in young children. Neuroimage 2010, 52:290-301.

10. Smith SM, Fox PT, Miller KL, Glahn DC, Fox PM, Mackay CE, Filippini N, Watkins $K E$, Toro R, Laird AR, Beckmann CF: Correspondence of the brain's functional architecture during activation and rest. Proc Natl Acad Sci U S A 2009, 106:13040-13045.

11. Seeley WW, Menon V, Schatzberg AF, Keller J, Glover GH, Kenna H, Reiss AL, Greicius MD: Dissociable intrinsic connectivity networks for salience processing and executive control. J Neurosci 2007, 27:2349-2356.

12. Beckmann CF, DeLuca M, Devlin JT, Smith SM: Investigations into restingstate connectivity using independent component analysis. Philos Trans R Soc Lond B Biol Sci 2005, 360:1001-1013

13. De Luca M, Beckmann CF, De Stefano N, Matthews PM, Smith SM: fMRI resting state networks define distinct modes of long-distance interactions in the human brain. Neuroimage 2006, 29:1359-1367.

14. Greicius MD, Krasnow B, Reiss AL, Menon V: Functional connectivity in the resting brain: a network analysis of the default mode hypothesis. Proc Natl Acad Sci U S A 2003, 100:253-258.

15. Bullmore $\mathrm{E}$, Sporns $\mathrm{O}$ : Complex brain networks: graph theoretical analysis of structural and functional systems. Nat Rev Neurosci 2009, 10:186-198.

16. Rubinov M, Sporns O: Complex network measures of brain connectivity: uses and interpretations. Neuroimage 2010, 52:1059-1069.

17. Calhoun VD, Liu J, Adali T: A review of group ICA for $\mathrm{FMRI}$ data and ICA for joint inference of imaging, genetic, and ERP data. Neuroimage 2009, 45 (1 Suppl):S163-172

18. Erhardt EB, Rachakonda S, Bedrick EJ, Allen EA, Adali T, Calhoun VD: Comparison of multi-subject ICA methods for analysis of $\mathrm{AMRI}$ data. Hum Brain Mapp 2011, 32:2075-2095.

19. Chang C, Glover GH: Effects of model-based physiological noise correction on default mode network anti-correlations and correlations. Neuroimage 2009, 47:1448-1459.

20. Fox MD, Zhang D, Snyder AZ, Raichle ME: The global signal and observed anticorrelated resting state brain networks. J Neurophysiol 2009, 101:3270-3283.

21. Cavaglia M, Dombrowski SM, Drazba J, Vasanji A, Bokesch PM, Janigro D: Regional variation in brain capillary density and vascular response to ischemia. Brain Res 2001, 910:81-93.

22. Weissenbacher A, Kasess C, Gerstl F, Lanzenberger R, Moser E, Windischberger 
C: Correlations and anticorrelations in resting-state functional connectivity MRI: a quantitative comparison of preprocessing strategies. Neuroimage 2009, 47:1408-1416.

23. Fox MD, Snyder AZ, Vincent JL, Corbetta M, Van Essen DC, Raichle ME: The human brain is intrinsically organized into dynamic, anticorrelated functional networks. Proc Natl Acad Sci U S A 2005, 102:9673-9678.

24. Fair DA, Cohen AL, Dosenbach NU, Church JA, Miezin FM, Barch DM, Raichle ME, Petersen SE, Schlaggar BL: The maturing architecture of the brain's default network. Proc Natl Acad Sci U S A 2008, 105:4028-4032.

25. Fransson P, Skiöld B, Horsch S, Nordell A, Blennow M, Lagercrantz H, Aden U: Resting-state networks in the infant brain. Proc Natl Acad Sci U S A 2007, 104:15531-15536

26. Schapiro MB, Schmithorst VJ, Wilke M, Byars AW, Strawsburg RH, Holland SK: BOLD fMRI signal increases with age in selected brain regions in children. Neuroreport 2004, 15:2575-2578.

27. Andrews-Hanna JR, Snyder AZ, Vincent JL, Lustig C, Head D, Raichle ME, Buckner RL: Disruption of large-scale brain systems in advanced aging. Neuron 2007, 56:924-935.

28. Biswal BB, Mennes M, Zuo XN, Gohel S, Kelly C, Smith SM, Beckmann CF Adelstein JS, Buckner RL, Colcombe S, Dogonowski AM, Ernst M, Fair D, Hampson M, Hoptman MJ, Hyde JS, Kiviniemi VJ, Kötter R, Li SJ, Lin CP, Lowe MJ, Mackay C, Madden DJ, Madsen KH, Margulies DS, Mayberg HS, McMahon K, Monk CS, Mostofsky SH, Nagel BJ, et al:: Toward discovery science of human brain function. Proc Nat/ Acad Sci U S A 2010, 107:4734-4739.

29. Jones DT, Machulda MM, Vemuri P, McDade EM, Zeng G, Senjem ML, Gunter JL, Przybelski SA, Avula RT, Knopman DS, Boeve BF, Petersen RC, Jack CR Jr.: Age-related changes in the default mode network are more advanced in Alzheimer disease. Neurology 2011, 77:1524-1531.

30. Tohka J, Foerde K, Aron AR, Tom SM, Toga AW, Poldrack RA: Automatic independent component labeling for artifact removal in $\mathrm{fMRI}$. Neuroimage 2008, 39:1227-1245.

31. Raichle ME, MacLeod AM, Snyder AZ, Powers WJ, Gusnard DA, Shulman GL: A default mode of brain function. Proc Natl Acad Sci U S A 2001, 98:676-682.

32. Lustig C, Snyder AZ, Bhakta M, O'Brien KC, MCAvoy M, Raichle ME, Morris JC, Buckner RL: Functional deactivations: change with age and dementia of the Alzheimer type. Proc Natl Acad Sci U S A 2003, 100:14504-14509.

33. Greicius MD, Srivastava G, Reiss AL, Menon V: Default-mode network activity distinguishes Alzheimer's disease from healthy aging: evidence from functional MRI. Proc Natl Acad Sci U S A 2004, 101:4637-4642.

34. Li SJ, Li Z, Wu G, Zhang MJ, Franczak M, Antuono PG: Alzheimer disease: evaluation of a functional MR imaging index as a marker. Radiology 2002, 225:253-259.

35. Wang L, Zang Y, He Y, Liang M, Zhang X, Tian L, Wu T, Jiang T, Li K: Changes in hippocampal connectivity in the early stages of Alzheimer's disease: evidence from resting state fMRI. Neuroimage 2006, 31:496-504.

36. Sorg C, Riedl V, Mühlau M, Calhoun VD, Eichele T, Läer L, Drzezga A, Förstl H, Kurz A, Zimmer C, Wohlschläger AM: Selective changes of resting-state networks in individuals at risk for Alzheimer's disease. Proc Natl Acad SCi USA 2007, 104:18760-18765.

37. Machulda MM, Ward HA, Borowski B, Gunter JL, Cha RH, O'Brien PC, Petersen RC, Boeve BF, Knopman D, Tang-Wai DF, Ivnik RJ, Smith GE, Tangalos EG, Jack CR Jr:. Comparison of memory fMRI response among normal, $\mathrm{MCl}$, and Alzheimer's patients. Neurology 2003, 61:500-506.

38. Celone KA, Calhoun VD, Dickerson BC, Atri A, Chua EF, Miller SL, DePeau K, Rentz DM, Selkoe DJ, Blacker D, Albert MS, Sperling RA: Alterations in memory networks in mild cognitive impairment and Alzheimer's disease: an independent component analysis. J Neurosci 2006, 26:10222-10231.

39. Sperling R, Chua E, Cocchiarella A, Rand-Giovannetti E, Poldrack R, Schacter $\mathrm{DL}$, Albert M: Putting names to faces: successful encoding of associative memories activates the anterior hippocampal formation. Neuroimage 2003, 20:1400-1410

40. Buckner RL, Sepulcre J, Talukdar T, Krienen FM, Liu H, Hedden T, AndrewsHanna JR, Sperling RA, Johnson KA: Cortical hubs revealed by intrinsic functional connectivity: mapping, assessment of stability, and relation to Alzheimer's disease. J Neurosci 2009, 29:1860-1873.

41. He Y, Wang L, Zang Y, Tian L, Zhang X, Li K, Jiang T: Regional coherence changes in the early stages of Alzheimer's disease: a combined structural and resting-state functional MRI study. Neuroimage 2007, 35:488-500

42. Gili T, Cercignani M, Serra L, Perri R, Giove F, Maraviglia B, Caltagirone C, Bozzali M: Regional brain atrophy and functional disconnection across Alzheimer's disease evolution. J Neurol Neurosurg Psychiatry 2011, 82:58-66.
43. Hedden T, Van Dijk KR, Becker JA, Mehta A, Sperling RA, Johnson KA, Buckner $\mathrm{RL}$ : Disruption of functional connectivity in clinically normal older adults harboring amyloid burden. J Neurosci 2009, 29:12686-12694.

44. Sheline YI, Raichle ME, Snyder AZ, Morris JC, Head D, Wang S, Mintun MA: Amyloid plaques disrupt resting state default mode network connectivity in cognitively normal elderly. Biol Psychiatry 2010, 67:584-587.

45. Zhang HY, Wang SJ, Liu B, Ma ZL, Yang M, Zhang ZJ, Teng GJ: Resting brain connectivity: changes during the progress of Alzheimer disease. Radiology 2010, 256:598-606

46. Zhang HY, Wang SJ, Xing J, Liu B, Ma ZL, Yang M, Zhang ZJ, Teng GJ: Detection of PCC functional connectivity characteristics in resting-state fMRI in mild Alzheimer's disease. Behav Brain Res 2009, 197:103-108.

47. Bai F, Watson DR, Yu H, Shi Y, Yuan Y, Zhang Z: Abnormal resting-state functional connectivity of posterior cingulate cortex in amnestic type mild cognitive impairment. Brain Res 2009, 1302:167-174.

48. Frings $L$, Dressel $K$, Abel S, Saur D, Kümmerer D, Mader I, Weiller C, Hüll M: Reduced precuneus deactivation during object naming in patients with mild cognitive impairment, Alzheimer's disease, and frontotemporal lobar degeneration. Dement Geriatr Cogn Disord 2010, 30:334-343.

49. Mormino EC, Smiljic A, Hayenga AO, Onami SH, Greicius MD, Rabinovici GD, Janabi M, Baker SL, Yen IV, Madison CM, Miller BL, Jagust WJ: Relationships between beta-amyloid and functional connectivity in different components of the default mode network in aging. Cereb Cortex 2011, 21:2399-2407.

50. Zhou J, Greicius MD, Gennatas ED, Growdon ME, Jang JY, Rabinovici GD, Kramer JH, Weiner M, Miller BL, Seeley WW: Divergent network connectivity changes in behavioural variant frontotemporal dementia and Alzheimer's disease. Brain 2010, 133 (Pt 5):1352-1367.

51. Machulda MM, Jones DT, Vemuri P, McDade E, Avula R, Przybelski S, Boeve BF, Knopman DS, Petersen RC, Jack CR Jr.: Effect of APOE e4 status on intrinsic network connectivity in cognitively normal elderly subjects. Arch Neurol 2011, 68:1131-1136.

52. Seeley WW: Divergent network connectivity changes in healthy APOE epsilon4 carriers: disinhibition or compensation? Arch Neurol 2011, 68:1107-1108.

53. Bai F, Watson DR, Shi Y, Wang Y, Yue C, YuhuanTeng, Wu D, Yuan Y, Zhang Z: Specifically progressive deficits of brain functional marker in amnestic type mild cognitive impairment. PLoS One 2011, 6:e24271.

54. Damoiseaux JS, Prater KE, Miller BL, Greicius MD: Functional connectivity tracks clinical deterioration in Alzheimer's disease. Neurobiol Aging 2011 Aug 13. [Epub ahead of print].

55. Tzourio-Mazoyer N, Landeau B, Papathanassiou D, Crivello F, Etard O, Delcroix N, Mazoyer B, Joliot M: Automated anatomical labeling of activations in SPM using a macroscopic anatomical parcellation of the MNI MRI singlesubject brain. Neuroimage 2002, 15:273-289.

56. Wang K, Liang M, Wang L, Tian L, Zhang X, Li K, Jiang T: Altered functional connectivity in early Alzheimer's disease: a resting-state fMRI study. Hum Brain Mapp 2007, 28:967-978.

57. Wang K, Jiang T, Liang M, Wang L, Tian L, Zhang X, Li K, Liu Z: Discriminative analysis of early Alzheimer's disease based on two intrinsically anticorrelated networks with resting-state fMRI. Med Image Comput Comput Assist Interv 2006, 9 (Pt 2):340-347.

58. Bai F, Liao W, Watson DR, Shi Y, Wang Y, Yue C, Teng Y, Wu D, Yuan Y, Jia J, Zhang Z: Abnormal whole-brain functional connection in amnestic mild cognitive impairment patients. Behav Brain Res 2011, 216:666-672.

59. Chen G, Ward BD, Xie C, Li W, Wu Z, Jones JL, Franczak M, Antuono P, Li SJ: Classification of Alzheimer disease, mild cognitive impairment, and normal cognitive status with large-scale network analysis based on resting-state functional MR imaging. Radiology 2011, 259:213-221.

60. Sanz-Arigita EJ, Schoonheim MM, Damoiseaux JS, Rombouts SA, Maris E, Barkhof F, Scheltens P, Stam CJ: Loss of 'small-world' networks in Alzheimer's disease: graph analysis of FMRI resting-state functional connectivity. PLoS One 2010, 5:e13788.

61. Supekar K, Menon V, Rubin D, Musen M, Greicius MD: Network analysis of intrinsic functional brain connectivity in Alzheimer's disease. PLoS Comput Biol 2008, 4:e1000100.

62. van den Heuvel MP, Stam CJ, Kahn RS, Hulshoff Pol HE: Efficiency of functional brain networks and intellectual performance. J Neurosci 2009, 29:7619-7624

63. Shirer WR, Ryali S, Rykhlevskaia E, Menon V, Greicius MD: Decoding subjectdriven cognitive states with whole-brain connectivity patterns. Cereb 
Cortex 2011 May 26. [Epub ahead of print].

64. Corder EH, Saunders AM, Strittmatter WJ, Schmechel DE, Gaskell PC, Small GW, Roses AD, Haines JL, Pericak-Vance MA: Gene dose of apolipoprotein E type 4 allele and the risk of Alzheimer's disease in late onset families. Science 1993, 261:921-923.

65. Filippini N, MacIntosh BJ, Hough MG, Goodwin GM, Frisoni GB, Smith SM, Matthews PM, Beckmann CF, Mackay CE: Distinct patterns of brain activity in young carriers of the APOE-epsilon4 allele. Proc Natl Acad Sci U S A 2009, 106:7209-7214.

66. Fleisher AS, Sherzai A, Taylor C, Langbaum JB, Chen K, Buxton RB: Resting-state BOLD networks versus task-associated functional MRI for distinguishing Alzheimer's disease risk groups. Neuroimage 2009, 47:1678-1690.

67. Sheline YI, Morris JC, Snyder AZ, Price JL, Yan Z, D'Angelo G, Liu C, Dixit S, Benzinger T, Fagan A, Goate A, Mintun MA: APOE4 allele disrupts resting state $\mathrm{fMRI}$ connectivity in the absence of amyloid plaques or decreased CSF Abeta42. J Neurosci 2010, 30:17035-17040.

68. Jack CR Jr., Lowe VJ, Weigand SD, Wiste HJ, Senjem ML, Knopman DS, Shiung MM, Gunter JL, Boeve BF, Kemp BJ, Weiner M, Petersen RC; Alzheimer's Disease Neuroimaging Initiative: Serial PIB and MRI in normal, mild cognitive impairment and Alzheimer's disease: implications for sequence of pathological events in Alzheimer's disease. Brain 2009, 132 (Pt 5):1355-1365.

69. Klunk WE, Engler H, Nordberg A, Wang Y, Blomqvist G, Holt DP, Bergström M, Savitcheva I, Huang GF, Estrada S, Ausén B, Debnath ML, Barletta J, Price JC, Sandell J, Lopresti BJ, Wall A,Koivisto P, Antoni G, Mathis CA, Långström B: Imaging brain amyloid in Alzheimer's disease with Pittsburgh CompoundB. Ann Neurol 2004, 55:306-319.

70. Drzezga A, Becker JA, Van Dijk KR, Sreenivasan A, Talukdar T, Sullivan C, Schultz AP, Sepulcre J, Putcha D, Greve D, Johnson KA, Sperling RA: Neuronal dysfunction and disconnection of cortical hubs in non-demented subjects with elevated amyloid burden. Brain 2011, 134 (Pt 6):1635-1646.
71. Sperling RA, Laviolette PS, O'Keefe K, O'Brien J, Rentz DM, Pihlajamaki M, Marshall G, Hyman BT, Selkoe DJ, Hedden T, Buckner RL, Becker JA, Johnson KA: Amyloid deposition is associated with impaired default network function in older persons without dementia. Neuron 2009, 63:178-188

72. Vannini P, Sullivan C, Schultz A, Putcha D, Vitolo O, Rentz D, Frey M, Becker AJ, Johnson KA, Sperling RA: Increased amyloid deposition is related to failure of habituation of the default network but preserved repetition suppression in the hippocampus during successful repetition encoding in cognitively normal older adults. Alzheimers Dement 2010, 6:S103-S104.

73. Buckner RL, Snyder AZ, Shannon BJ, LaRossa G, Sachs R, Fotenos AF, Sheline YI, Klunk WE, Mathis CA, Morris JC, Mintun MA: Molecular, structural, and functional characterization of Alzheimer's disease: evidence for a relationship between default activity, amyloid, and memory. J Neurosci 2005, 25:7709-7717.

74. Lorenzi M, Beltramello A, Mercuri NB, Canu E, Zoccatelli G, Pizzini FB, Alessandrini F, Cotelli M, Rosini S, Costardi D, Caltagirone C, Frisoni GB: Effect of memantine on resting state default mode network activity in Alzheimer's disease. Drugs Aging 2011, 28:205-217.

75. Sauer J, ffytche DH, Ballard C, Brown RG, Howard R: Differences between Alzheimer's disease and dementia with Lewy bodies: an fMRI study of task-related brain activity. Brain 2006, 129 (Pt 7):1780-1788.

76. Galvin JE, Price JL, Yan Z, Morris JC, Sheline YI: Resting bold fMRI differentiates dementia with Lewy bodies vs Alzheimer disease. Neurology 2011, 76:1797-1803.

77. Seeley WW, Crawford RK, Zhou J, Miller BL, Greicius MD: Neurodegenerative diseases target large-scale human brain networks. Neuron 2009, 62:42-52.

doi:10.1186/alzrt100

Cite this article as: Vemuri $P$, et al:: Resting state functional MRI in

Alzheimer's Disease. Alzheimer's Research \& Therapy 2012, 4:2. 